\title{
Can lifestyle factors be the key in deciding the COVID-19 outcome?
}

Ramakrishnan Angarai Ganesan ${ }^{1}, \mathrm{PhD}$, Kanishka Sharma ${ }^{1}, \mathrm{PhD}$, Gangadhar BN ${ }^{2}, \mathrm{MD}$, Author Affiliations

1. Department of Electrical Engineering, Indian Institute of Science, Bengaluru, India

2. Ethics and Medical Registration Board, National Medical Commission, New Delhi, India

Corresponding author: Prof. Ramakrishnan Angarai Ganesan, Department of Electrical Engineering, Indian Institute of Science, Bengaluru, India.

Email: agr@iisc.ac.in

\begin{abstract}
The COVID-19 recovery rate of $97.3 \%$ and the death per million of 345 in India are better than the corresponding values in the USA and most of Europe despite better health infrastructure in these countries. The mean COVID fatality rate of Europe and a few countries in America is seven times that of India. This warrants a systematic study of the factors behind this conspicuous disparity. It is time to study lifestyle and other factors that may be related to recovery with minimal medical intervention or serious complications, leading to belated recovery and sometimes mortality. Obesity and excessive consumption of soft drinks, red meat and processed food may have a role to play in the European and American countries. On the other hand, the use of turmeric, black pepper, ginger in daily cooking, consumption of Indian gooseberry, Tulasi, different decoctions (Kashaya) and practice of various immune-boosting breathing exercises including yoga might have had a role in India. A detailed study involving a sizable number of cases of recovery and death in India, USA and some European countries will throw light on these factors behind the significant differences. The results shall provide crucial learning to the world for managing future waves and pandemics.
\end{abstract}

Keywords: COVID-19, fatality, recovery rate, immunity, causative factors, diet, soft drinks, ultra-processed meat, adaptogens, sleep, lifestyle. 


\section{Introduction}

The whole world has been suffering the assault of coronavirus for two years now, and the end is not yet in sight. Given that the countries with advanced medical facilities ${ }^{1}$ have not been doing as well as some of the countries with lower per capita income, there is a need to look for other reasons such as lifestyle factors that might be behind this disparity. It appears that humanity needs to find newer ways to address such pandemics beyond merely modern medical approaches.

Table 1 lists the population and the COVID statistics ${ }^{2}$ of a few countries in the American continent and about 30 countries in Europe chosen in such a way that the total population of all these countries put together is nearly the same as that of India. The statistics suggest that the recovery and fatality rates in India are better than the countries such as Belgium, France, Hungary, Italy, UK, and USA. It requires detailed studies as to what the reasons are behind India, Japan, Finland and Norway doing better in terms of lower mortality rate than USA and rest of Europe. However, Finland and Norway are small with their population being a fraction of Japan, whose population is a fraction of India's. Further, the current recovery rates in these two countries are below $21 \%$. Thus, we mainly focus on India. Is it because most Indians eat home-cooked, rather than processed food? Is it their dependence on immune-boosting traditional herbs, medicines, kashaya, etc.? Is it the reduced use of recirculating air conditioners, or better sleep habits? Is it due to the lower consumption of soft drinks, refined flour and ultraprocessed meat in India and Japan? In this paper, we only look for logical associations from the known scientific literature. However, a systematic research and study on these factors will be valuable to the whole of humanity and the results of the study will be useful to take steps on public health in the Covid-19 pandemic.

Some believe that COVID deaths in India are underreported. However, we must note that Dr. Anthony Fauci (Chief Medical Advisor to US President) publicly stated in May 2021 
that USA has undercounted COVID fatalities and it might be 9 lakhs ${ }^{3}$. The numbers from many countries may have uncertainties.

\section{POSSIBLE CAUSES FOR THE RESILIENCE}

As of 8 January 2022, total COVID cases per million population in USA, France, and UK are 181061, 175767, and 209477, respectively, as against 25253 in India ${ }^{2}$. The infection or incidence rate in these countries is 7 to 8 times that of India. The number of active cases in India is about 0.5 million, whereas it is over 17.4 million in USA. On the other hand, the population of USA of 334 million is less than one-fourth the population of India (1400 million). The number of active cases in USA is $43.3 \%$ of the total number of active cases in the world. This indicates that the turnaround of semipositive individuals in India is faster than that in the USA. The current figures correspond to recovery rates of $69.7 \%, 73.4 \%, 74.8$, and $97.3 \%$ in USA, France, UK and India, respectively. The number of lives lost to COVID-19 as of 8 Jan 2022 are 2570, 2193, and 1912 per million of population in the USA, UK, and France, whereas the corresponding figure is 345 in India $^{2}$. The nature of medical intervention and medicines used in USA, Europe and India are comparable. Being countries ranked higher in developmental indices ${ }^{1}$, the differences in healthcare favor these countries and not India. Hence, the differences in the incidence, recovery and fatality rates merit explanation by factors beyond the healthcare system. The following subsections discuss the possible lifestyle factors.

\section{Consumption of soft drinks.}

Mexico and the USA are countries with the highest carbonated soft drink (CSD) consumption, with Germany and Brazil coming next. Yearly consumption of CSD in the United States, Mexico, Germany and Brazil were 1496, 1489, 1221 and 537 bottles per person ${ }^{4}$, respectively, in 2016 , as compared to 44 bottles per capita ${ }^{5}$ in India. The mortality rate per million population in Brazil, USA, Mexico, and Germany are 2885, 2570, 2291, and 1361 respectively, as 
compared to 345 in India ${ }^{2}$. Thus, there is a high correlation between the consumption of soft drinks and the COVID fatality figures in these countries. Further, the recovery rates in USA, Germany, and Mexico are less than $90 \%$, whereas it is $97.3 \%$ in India. Of course, correlation does not imply causation; however, it is worth studying whether this could be one of the key factors. Considering the fact that not everyone in the population consume these CSDs regularly, the daily consumption of people who consume this more often must be above a litre in USA and Mexico. Most of the soft drinks available in the market are acidic with a $\mathrm{pH}$ around 2 to 3. Regular consumption of drinks with such acidic $\mathrm{pH}$ is clearly an avoidable health issue. Further, excessive consumption of sugar or sugar substitutes increases the likelihood of obesity and diabetes $^{6}$, proven to be the greatest risk factors in COVID-19. Centre for Disease Control (CDC), USA has stated that obesity is linked to impaired immunity, decreased lung capacity, and increases the risk of hospitalization three times in the case of COVID-19 infection ${ }^{7}$. Adult obesity rates are very high in the United States, Mexico, and Hungary, while they are very low in Japan. As per American Diabetes Association, people with diabetes are more likely to have more severe symptoms and complications ${ }^{8}$ when infected with COVID-19.

\section{Refined sugar, flour, and ultra-processed meat versus dietary fibre.}

Ian Myles from the National Institute of Allergy and Infectious Diseases, USA reported in 2014 that the Western diet reduced the immunity of people ${ }^{9}$. A food industry analysis report ${ }^{10}$ says that fast food accounted for more than $50 \%$ of sales in the restaurant sector in 2020 . There are more than 200,000 fast-food restaurants in the United States and in 2015, revenue due to fast food was $\$ 200$ billion in USA, which was more than one-third the fast-food revenue of the world of $\$ 570$ billion. Fast-food chains are less than $5 \%$ of India's food services market ${ }^{11}$. This type of food is characterized by high amounts of saturated and omega- 6 fatty acids, sugar

and sea salt, and reduced omega- 3 fat $^{12}$. The major culprit is refined sugar. When sugar is consumed, sucrose as a biomolecule needs to be broken down into glucose and fructose. The 
glucose gets absorbed in the blood, but the fructose is sent to the hepatic tissues to be broken down further. The liver can manage this when provided in small amounts such as from an apple fruit; however, the abundance of this molecule present in regular processed food overwhelms liver's capability. This results in forced conversion of this extra fructose to fat which gets deposited on hepatic tissues and impairs its functioning and creates insulin resistance. Being an important innate immune organ, its damage could lead to susceptibility towards pathogens ${ }^{13}$. Most of the bread, cakes, donuts, muffins, and buns used in the burgers are made of refined flour and sugar, both of which have no nutrients for the body. When overconsumed, sugar is also a risk factor for osteoporosis by increasing inflammation, reducing calcium intake, and increasing urinary calcium excretion ${ }^{14}$.

A 2013 study ${ }^{15}$ has reported that the per capita consumption of lamb meat is the least in India out of a list of 44 countries, where sheep and goat meat is consumed. Greece, UK, and France have the 6th, 11th, and 14th highest consumption. Similarly, Argentina, USA, and Brazil are the countries with the second, fourth and fifth-highest per capita beef consumption, whereas India's is 52nd. High consumption of red meat is associated with higher circulating levels of gamma-glutamyltransferase and $\mathrm{C}$ reactive $\operatorname{protein}^{16}$, whose concentrations in blood are directly proportional to the severity of inflammation. Further, red meat contains high levels of oxymyoglobin and deoxyhemoglobin, which act as catalysts in oxidative stress and can be a basis for cancer $^{17}$. Heme catalyzed oxidations can damage lipids, proteins, DNA, and other nucleic acids and various components of biological systems. A study on human-like Neu5Gcdeficient mice reported that red meat derived glycan (Neu5Gc) can initiate inflammation and cancer progression. Long-term exposure to Neu5Gc resulted in a five-fold increase in the incidence of carcinomas $^{18}$. Consumption of processed meat is associated with $42 \%$ higher risk of coronary heart disease and $19 \%$ higher risk of diabetes mellitus than that of red meat. Interestingly, the USA is again in the top 10 countries consuming processed meat ${ }^{19}$. Processed 
meat is even less nutritious than fresh meat due to protein oxidation ${ }^{20}$ and it is also carcinogenic $^{21}$. Thus, high consumption of red and processed meat significantly increases the co-morbidities associated with COVID-19.

In India, plant-based adaptogens are utilized as ingredients in the daily diet or as a supplement in their original form. Adaptogens have been consumed in India for thousands of years in the form of spices such as turmeric, ginger, anise, cinnamon, clove, juices such as giloy, Indian gooseberry, tulasi, and medicines such as ashwagandha, sarpagandha, and shankhapushpi. Adaptogens have anti-inflammatory effects and help the body deal with stress. They modulate the immune response as well as detoxify and repair the compromised cells damaged from the oxidative stress of the cells induced by viruses ${ }^{22}$.

Japan has a high consumption of rice, soybean products, vegetables, fish, green tea and seasonings and a low consumption of sugars, dairy, animal fats, confectionaries and sugarsweetened beverages. Thus, the Japanese diet is one of the healthiest in the world, and their mean life expectancy is higher than that of the Western world.

\section{Gut microbiota and immunity}

Gut bacteria in the cecum and large intestine of humans produce short-chain fatty acids (SCFAs) from indigestible plant polysaccharides (fibres) present in minimally or unprocessed food. SCFAs are important factors in regulating the metabolism of fatty acids, glucose, and cholesterol. They play a crucial role in energy metabolism ${ }^{23}$ and immunoregulation ${ }^{24}$ by epithelial barrier function, regulating proliferation and tumour suppression and inducing cytokine production. Progressive loss of good bacteria and microbial diversity in the gut has been seen as a reason for chronic diseases increasing in western countries ${ }^{25}$. On the other hand, low body mass index ${ }^{26}$, reduced consumption of carcinogenic components such as heterocyclic 
amines, polycyclic aromatic hydrocarbons, and emulsifier ${ }^{25}$ are associated with the traditional Indian diet mostly derived from plant sources. A common Indian diet is rich in phytochemicals (anthocyanin, polyphenols, alkaloids, flavonoids, carotenoids, tocopherols, reducing acids, etc.) and dietary fibres, which help in promoting diverse and stable bacterial growth and cholesterol excretion from the body, respectively ${ }^{27}$. Fibres and polyphenols present in plant diet promote growth of Lactobacillus and other lactic acid bacteria which are anti-inflammatory, promoting cardiovascular health ${ }^{28}$. Western diet has less plant-based dietary fibres and more refined flour. India and African countries use raw grains and local vegetables as essential part of their daily diet. This difference in diet selection is directly related to the flourishing gut microbiota in Indian population, providing them a possible advantage of enhanced immunity and anti-inflammatory traits.

\section{Social factors}

In India and Africa, the population is exposed to microbial load at an early age. This interaction provides an advantage of broad-based immunity. A comparative analysis of Indian and American new-borns revealed higher levels of immune-responsive cells such as dendritic cells, monocytes, natural killer $(\mathrm{NK})$ cells, memory CD4 $+\mathrm{T}$ cells, and naïve B cells in the Indian children ${ }^{29}$. Also, higher social interactions and high population density provide a continuous exchange of microbes from individuals which may act as a trigger to a more proactive cell-mediated immune system in Indians.

\section{Sleep hygiene and immunity}

Disrupted sleep and psychosocial stress cause anxiety which leads to dysregulated endocrino-immunological responses ${ }^{30}$. Increase in cortisol levels, steroid insensitivity, proinflammatory mediators and cytokine reaction and decrease in circulating neural growth factor and brain-derived neurotrophic factor are manifestations of this disruption. This cascade 
ultimately triggers a dysregulated immune response by activating "cytokine-hypothalamicpituitary-adrenal-cytokine" axis.

Negative ions in the air, generated by water, enhance the cytotoxic activity of natural killer cells and inhibit tumour growth ${ }^{31}$. Negative ions have been observed to show antimicrobial properties comparable to UV light in rats and prevent tuberculosis transmission in guinea pigs ${ }^{32}$. The concentration of negative ions is higher in the air during early mornings and diminishes in late mornings and afternoon. Most Indians are early risers due to which they get exposed to negative ions which may positively impact their immunity ${ }^{33}$. However, there is a lack of empirical studies with interaction of immune system function and negative ions.

\section{Ventilation in houses and natural air circulation}

In our earlier work ${ }^{34}$, we stressed upon ventilation of the COVID ICUs in order to prevent the contaminated aerosol remaining due to the recirculation of air by the airconditioning systems. According to CDC guidelines also, CoV-2 viral particles spread between people more readily indoors than outdoors ${ }^{35}$. In the United States, $90 \%$ of the households have air-conditioning systems installed, whereas in India, it is only 5\%. Hence, natural air and cross ventilation are key considerations in the construction of Indian households ${ }^{36}$. In USA and other western countries, air-conditioning is an essential element in the household and offices and

may have increased the transmission of infection ${ }^{37}$. However, the urban areas in India have similar issues, which was reflected in the preliminary cases of COVID-19 reported in spring season of 2020 .

\section{Role of yoga, pranayama, and traditional medicine}

There has been a major revival of yoga, pranayama and Ayurveda in India due to the first and second waves of coronavirus in India. Many yoga teachers prescribed specific yoga postures and pranayama techniques that activate the lymph and immune system. This yoga lifestyle is widely prevalent in India. Yoga and Tai chi are both popular in Japan, and the media 
covered the elderly population practicing Tai chi during the lockdown. In India, practitioners of traditional medicine suggested home remedies in terms of decoctions made from herbs and adaptogens, which were widely followed by the public. The AYUSH department of the Ministry of Health also actively promoted Ayurvedic immunity-boosting measures for self-care. While it is difficult to gauge the exact role and effect these played in reducing the infection rate or improving the recovery rate, it is reasonable to assume that they did contribute positively.

\section{CONCLUSION}

Since the novel coronavirus has affected the whole world, we have adequate data spread out in the various hospitals of the world. All the possible factors that we have mentioned in this paper affect the human immune system as per peer-reviewed publications in good journals. There are differences between countries in health infrastructure available to public. India is still far behind in terms of health facilities and hospital availability per capita ${ }^{38}$. However, the provided survey of published literature indicates the possible influence of the lifestyle factors on public health and proneness to viral infections and recovery. Thus, focused studies are required on the clinical details collected from a large number of COVID-19 hospitalized patients in India, USA, Brazil and a few European countries to get confirmed knowledge about the factors behind the differences among the COVID-19 statistics of different countries. Details such as the age, preexisting health conditions, food habits and other lifestyle factors must be considered in the study, for a significant percentage of the active cases, recovered people, and those who did not survive the infection. The learnings from such a study will be invaluable to governments, health system administrators, and humanity as a whole to be able to manage future pandemics more effectively.

\section{Contributors}


RAG conceptualized the draft. KS did the literature search. RAG and KS jointly wrote the manuscript draft and also verified the underlying data. BNG added critical inputs and edited the manuscript. All the authors reviewed and approved the final manuscript.

\section{Declaration of interests}

We declare that there are no competing interests.

\section{Acknowledgments}

The authors thank DST-SATYAM, Government of India for funding this study under the COVID Mission. Project ref: DST/SATYAM/COVID/19/2020/251(G). 


\section{References}

1. Tandon A, Murray CJ, Lauer JA, Evans DB. Measuring overall health system performance for 191 countries. Geneva: World Health Organization. 2000.

2. Worldometer: COVID-19 Coronavirus pandemic. [Internet]. [cited 6 Jan 2022]. Available from: https://www.worldometers.info/coronavirus/

3. US has undercounted its COVID deaths, says Anthony Fauci. Youtube.com. [cited 6 Jan 2022]. Available from: https://www.youtube.com/watch?v=1bleHZ66IWI

4. Per capita soft drink volume U.S. 2013-2026 | Statista [Internet]. Statista. [cited 6 Jan 2022]. Available from: https://lb-aps-frontend.statista.com/statistics/306841/us-percapita-consumption-of-csd-by-state/

5. India's per-capita soft drink consumption to be almost double to 84 bottles a year by 2021: VBL [Internet]. The Economic Times. [cited 6 Jan 2022]. Available from: https://economictimes.indiatimes.com/industry/cons-products/food/indias-per-capitasoft-drink-consumption-to-be-almost-double-to-84-bottles-a-year-by-2021vbl/articleshow/68950836.cms

6. Basu S, McKee M, Galea G, Stuckler D. Relationship of soft drink consumption to global overweight, obesity, and diabetes: a cross-national analysis of 75 countries. American Journal of Public Health. 2013 Nov;103(11):2071-7.

7. Obesity, Race/Ethnicity, and COVID-19 [Internet]. Centers for Disease Control and Prevention. 2021 [cited 6 Jan 2022]. Available from: https://www.cdc.gov/obesity/data/obesity-and-covid-19.html

8. Frequently Asked Questions: COVID-19 and Diabetes |ADA [Internet]. Diabetes.org. [cited 6 Jan 2021]. Available from: https://www.diabetes.org/coronavirus-covid19/how-coronavirus-impacts-people-with-diabetes

9. Myles IA. Fast food fever: reviewing the impacts of the Western diet on immunity. Nutrition journal. 2014 Dec;13(1):1-7.

10. Fast Food Industry Analysis 2020 - Cost \& Trends [Internet]. Franchisee Resource Center. 2021 [cited 9 Jan 2022]. Available from: https://www.franchisehelp.com/industry-reports/fast-food-industry-analysis-2020cost-trends/

11. Bansal S. Indians still hungry for fast food: Report [Internet]. Mint. 2021 [cited 9 Jan 2022]. Available from: https://www.livemint.com/news/india/indians-still-hungry-forfast-food-report-11613997244459.html

12. Myles IA, Pincus NB, Fontecilla NM, Datta SK. Effects of parental omega-3 fatty acid intake on offspring microbiome and immunity. PLoS One. 2014 Jan 29; 9(1): e87181.

13. Zhan YT, An W. Roles of liver innate immune cells in nonalcoholic fatty liver disease. World Journal of Gastroenterology. 2010 Oct 7; 16(37):4652.

14. DiNicolantonio JJ, Mehta V, Zaman SB, O’Keefe JH. Not salt but sugar as aetiological in osteoporosis: A review. Missouri Medicine. 2018 May; 115(3):247.

15. Which country consumes the most lamb meat? [Internet]. Helgilibrary.com. 2021 [cited 7 Jan 2022]. Available from: https://www.helgilibrary.com/charts/which-countryconsumes-the-most-lamb-meat/

16. Montonen J, Boeing H, Fritsche A, Schleicher E, Joost HG, Schulze MB, Steffen A, Pischon T. Consumption of red meat and whole-grain bread in relation to biomarkers of obesity, inflammation, glucose metabolism and oxidative stress. European journal of nutrition. 2013 Feb 1;52(1):337-45. 
17. Tappel A. Heme of consumed red meat can act as a catalyst of oxidative damage and could initiate colon, breast and prostate cancers, heart disease and other diseases. Medical hypotheses. 2007 Jan 1;68(3):562-4.

18. Samraj AN, Pearce OM, Läubli H, Crittenden AN, Bergfeld AK, Banda K, Gregg CJ, Bingman AE, Secrest P, Diaz SL, Varki NM. A red meat-derived glycan promotes inflammation and cancer progression. Proceedings of the National Academy of Sciences. 2015 Jan 13;112(2):542-7.

19. Processed meat marker - growth, trends, COVID-19 impact, and forecasts (2021-2016) [Internet]. 2021 [cited 7 Jan 2022]. Available from: https://www.mordorintelligence.com/industry-reports/global-processed-meat-marketindustry

20. Soladoye OP, Juárez ML, Aalhus JL, Shand P, Estévez M. Protein oxidation in processed meat: Mechanisms and potential implications on human health. Comprehensive Reviews in Food Science and Food Safety. 2015 Mar;14(2):106-22.

21. Cross AJ, Leitzmann MF, Gail MH, Hollenbeck AR, Schatzkin A, Sinha R. A prospective study of red and processed meat intake in relation to cancer risk. PLoS Medicine. 2007 Dec;4(12):e325.

22. Panossian A, Brendler T. The role of adaptogens in prophylaxis and treatment of viral respiratory infections. Pharmaceuticals. 2020 Sep;13(9):236.

23. Den Besten G, Van Eunen K, Groen AK, Venema K, Reijngoud DJ, Bakker BM. The role of short-chain fatty acids in the interplay between diet, gut microbiota, and host energy metabolism. Journal of Lipid Research. 2013 Sep 1;54(9):2325-40.

24. Maslowski KM, Vieira AT, Ng A, Kranich J, Sierro F, Yu D, Schilter HC, Rolph MS, Mackay F, Artis D, Xavier RJ. Regulation of inflammatory responses by gut microbiota and chemoattractant receptor GPR43. Nature. 2009 Oct; 461(7268):1282-6.

25. Shondelmyer K, Knight R, Sanivarapu A, Ogino S, Vanamala JK. Focus: Nutrition and Food Science: Ancient Thali diet: gut microbiota, immunity, and health. The Yale Journal of Biology and Medicine. 2018 Jun;91(2):177.

26. Appleby PN, Thorogood M, Mann JI, Key TJ. Low body mass index in non-meat eaters: the possible roles of animal fat, dietary fibre and alcohol. International Journal of Obesity. 1998 May;22(5):454-60.

27. Rao BN. Bioactive phytochemicals in Indian foods and their potential in health promotion and disease prevention. Asia Pacific Journal of Clinical Nutrition. 2003 Mar $1 ; 12(1)$.

28. Tomova A, Bukovsky I, Rembert E, Yonas W, Alwarith J, Barnard ND, Kahleova H. The effects of vegetarian and vegan diets on gut microbiota. Frontiers in Nutrition. 2019 Apr 17; 6:47.

29. Rathore DK, Holmes TH, Nadeau KC, Mittal P, Batra A, Rosenberg-Hasson Y, Sopory S, Gupta R, Chellani HK, Aggarwal KC, Bal V. Differences in multiple immune parameters between Indian and US infants. PloS one. 2018 Nov 16; 13(11): e0207297.

30. Nami M, Mehrabi S, Kamali AM, Kazemiha M, Carvalho J, Derman S, Lakey-Betia J, Vasquez V, Kosagisharaf R. A new hypothesis on anxiety, sleep insufficiency, and viral infections; reciprocal links to consider in today's "world vs. COVID-19" endeavors. Frontiers in Psychiatry. 2020;11.

31. Yamada R, Yanoma S, Akaike M, Tsuburaya A, Sugimasa Y, Takemiya S, Motohashi H, Rino Y, Takanashi Y, Imada T. Water-generated negative air ions activate NK cell and inhibit carcinogenesis in mice. Cancer Letters. 2006 Aug 8;239(2):190-7.

32. Escombe AR, Moore DA, Gilman RH, Navincopa M, Ticona E, Mitchell B, Noakes C, Martínez C, Sheen P, Ramirez R, Quino W. Upper-room ultraviolet light and negative 
air ionization to prevent tuberculosis transmission. PLoS Medicine. 2009 Mar; 6(3):e1000043.

33. Jiang SY, Ma A, Ramachandran S. Negative air ions and their effects on human health and air quality improvement. International Journal of Molecular Sciences. 2018 Oct; 19(10):2966.

34. Ganesan RA, Sharma K. Redesign of the COVID-19 ICUs to save the Corona warriors. In 2020 IEEE Bangalore Humanitarian Technology Conference (B-HTC) 2020 Oct 8 (pp. 1-6). IEEE

35. Ventilation in Buildings: [Internet]. Center for Disease Control and Prevention. 2021 [cited 8 Jan 2022]. Available from: https://www.cdc.gov/coronavirus/2019ncov/community/ventilation.html

36. Holst, A. (2020). Global AC penetration rate by country 2016. In Statista. https://www.statista.com/statistics/911064/worldwide-air-conditioning-penetrationrate-country/

37. Most air conditioning systems don't protect against the coronavirus. In some cases, they can actually facilitate spread [Internet]. Usatoday.com. 2021 [cited 7 Jan 2022]. Available from: https://www.usatoday.com/story/news/health/2020/07/15/covid-airconditioning-could-facilitate-coronavirus-airborne-spread/5429919002/

38. Hospital beds (per 1,000 people) [Internet]. data.worldbank.org. 2021 [cited 7 Jan 2022]. Available from: https://data.worldbank.org/indicator/SH.MED.BEDS.ZS

39. GDP per Capita. [Internet]. 2021 [cited 8 Jan 2022]. Available from: https://tradingeconomics.com/

Table 1

Comparison of COVID-19 recovery \& fatality rates of Europe and America ${ }^{2}$ with India and Japan as on 8 January 2022. The rank of the overall efficiency of the health system of the countries is as per $\mathrm{WHO}^{1}$. 'NA' implies that the rank is not available. 'N/A' implies that it is not applicable.

\begin{tabular}{llcclcc}
\hline Country & $\begin{array}{l}\text { Lives } \\
\text { lost/mil. } \\
\text { populat }\end{array}$ & $\begin{array}{r}\text { Rank of } \\
\text { health } \\
\text { system }\end{array}$ & $\begin{array}{l}\text { Per capita } \\
\text { Income } \\
\text { in US } \$\end{array}$ & $\begin{array}{l}\text { Reco- } \\
\text { very } \\
\text { Rate } \%\end{array}$ & $\begin{array}{l}\text { Popula- } \\
\text { tion in } \\
\text { million }\end{array}$ & $\begin{array}{c}\text { Total lives } \\
\text { lost till } \\
\text { 8 Jan 2022 }\end{array}$ \\
\hline India & 345 & 112 & 1750 & 97.3 & 1400.6 & 483463 \\
Finland & 295 & 31 & 47500 & 15.1 & 5.55 & 1638 \\
Norway & 246 & 11 & 91500 & 20.5 & 5.49 & 1350 \\
Japan & 146 & 10 & 35200 & 98.0 & 125.9 & 18400 \\
------------- & ----------- & ---------- & ------------ & ------ & ----------- & ------------- \\
Bulgaria & 4,582 & 102 & 8900 & 79.7 & 6.87 & 31,471 \\
Bosnia & 4,175 & 99 & 6180 & 64.6 & 3.25 & 13,568 \\
Hungary & 4,134 & 66 & 17100 & 88.7 & 9.65 & 39,780 \\
N.Macedonia & 3,846 & 89 & 5500 & 92.6 & 2.08 & 8,012 \\
Georgia & 3,559 & 114 & 4850 & 94.5 & 3.98 & 14,156 \\
Croatia & 3,157 & 43 & 16300 & 92.7 & 4.07 & 12,841 \\
Slovakia & 3,099 & 62 & 20500 & 93.9 & 5.46 & 16,933 \\
Romania & 3,098 & 99 & 11900 & 95.9 & 19.04 & 58,994 \\
Brazil & 2,884 & 125 & 11100 & 96.3 & 214.8 & 619,878 \\
Lithuania & 2,824 & 73 & 16000 & 92.6 & 2.66 & 7,524 \\
Slovenia & 2,717 & 38 & 26000 & 92.3 & 2.08 & 5,650 \\
\hline
\end{tabular}




\begin{tabular}{|c|c|c|c|c|c|c|}
\hline Poland & 2,639 & 50 & 17400 & 88.3 & 37.8 & 99,720 \\
\hline USA & 2,570 & 37 & 56200 & 69.7 & 333.9 & 858,346 \\
\hline Argentina & 2,563 & 75 & 12500 & 97.1 & 45.8 & 117,428 \\
\hline Colombia & 2,519 & 22 & 6200 & 95.2 & 51.7 & 130,250 \\
\hline Latvia & 2,507 & 105 & 16100 & 93.0 & 1.85 & 4,650 \\
\hline Belgium & 2,439 & 21 & 47400 & 83.0 & 11.67 & 28,459 \\
\hline Italy & 2,299 & 2 & 34600 & 91.0 & 60.3 & 138,697 \\
\hline Mexico & 2,291 & 61 & 9900 & 81.6 & 131.0 & 300,101 \\
\hline UK & 2,193 & 18 & 41100 & 76.4 & 68.4 & 150,057 \\
\hline Greece & 2,055 & 14 & 23200 & 72.6 & 10.3 & 21,263 \\
\hline Spain & 1,922 & 7 & 32000 & 91.1 & 46.8 & 89,934 \\
\hline France & 1,912 & 1 & 42600 & 73.4 & 65.5 & 125,206 \\
\hline Portugal & 1,879 & 12 & 23600 & 92.7 & 10.15 & 19,071 \\
\hline Kosovo & 1,608 & NA & 4300 & 97.4 & 1.86 & 2,991 \\
\hline Austria & 1,524 & 9 & 49000 & 94.3 & 9.1 & 13,844 \\
\hline Sweden & 1,504 & 12 & 58100 & 85.5 & 10.2 & 15,331 \\
\hline Serbia & 1,484 & NA & 7100 & 94.7 & 8.7 & 12,890 \\
\hline Estonia & 1,472 & 77 & 19700 & 91.3 & 1.3 & 1,954 \\
\hline Luxembourg & 1,437 & 16 & 110000 & 86.9 & 0.64 & 922 \\
\hline Switzerland & 1,420 & 20 & 85680 & 73.1 & 8.7 & 12,425 \\
\hline Germany & 1,361 & 25 & 43800 & 89.5 & 84.2 & 114,586 \\
\hline Netherlands & 1,226 & 17 & 53800 & 84.8 & 17.2 & 21,073 \\
\hline Albania & 1,125 & 55 & 5200 & 93.5 & 2.9 & 3,233 \\
\hline Belarus & 603 & 72 & 6700 & 99.0 & 9.4 & 5,699 \\
\hline Denmark & 579 & 34 & 63500 & 73.7 & 5.8 & 3,371 \\
\hline Mean/Total & $\begin{array}{l}2383 \\
\text { (maen) }\end{array}$ & N/A & & - & $\begin{array}{c}1309.11 \\
\text { (total) }\end{array}$ & $\begin{array}{c}3,120,308 \\
\text { (total) }\end{array}$ \\
\hline
\end{tabular}

